\title{
Helena María da Silva Gomes y Aline Signoret Dorcasberro, Temas sobre la adquisición de una segunda lengua. 2a. ed. México, Trillas, 2005.
}

La segunda edición del manual Temas sobre la adquisición de una segunda lengua, es un acontecimiento importante ya que se trata de un libro indispensable para quienes se interesan por la investigación que actualmente se realiza sobre la adquisición y la enseñanza de una segunda lengua y por líneas de estudio afines.

Para el comentario del volumen que nos ocupa elaboré este breve resumen "aplicado" de los capítulos: 4. La edad y el desarrollo de Lengua Extranjera; 5. Las variables afectivas y el desarrollo de Lengua Extranjera y 6. Las variables cognoscitivas y el desarrollo de Lengua Extranjera, capítulos tan interesantes y sugerentes como los otros cuatro que integran la obra.

Plasticidad, lateralización en la pubertad, vía alternativa, pidginización, pulsión cognoscitiva, motivación aversiva, estrategias de reducción, estrategias de expansión, inferencia intralingual, inferencia extralingual, verificación receptiva, todo esto no es una lista de palabras obscenas como diría la maestra Alma Ortiz, de aquellos términos difíciles de comprender, pero sí puede convertirse en una lista de conceptos incómodos si como profesores de lenguas no nos detenemos a meditar sobre ellos.

Veamos algunos ejemplos:
Tuve un alumna Gina, noruega de 70 años de edad que nunca había salido de su país, jamás intentó aprender otro idioma y por fortuna, eso creo, nunca leyó a Lenneberg quien plantea que "la plasticidad es un requisito esencial para adquirir un idioma. Si un sujeto no adquiere una lengua materna, una segunda o tercera lengua durante el tiempo que transcurre de los dos años a la pubertad, entonces la adquisición será imposible", (p. 181) a su edad, Gina había dejado un poco lejos ya la pubertad y sin embargo adquirió el suficiente español en seis semanas como para decirme que se sentía muy triste sin su esposo (había quedado viuda), muy sola, que nunca antes había dependido de alguien y que ahora se sentía muy mal porque no podía ir a ningún lado sola, no podía comunicarse con su nuera porque hablaban distintas lenguas y ésta no intentaba comunicarse con ella. Gina aprendió lo suficiente para agradecerme lo que pude enseñar1e, cosa que como maestra fue mi mejor pago. Gina no sólo logrólo que Lenneberg no consideraba posible, sino que lo hizo en un periodo más corto de lo que lo habría hecho un niño, gracias a su madurez cognoscitiva la cual, según Inhelder y Piaget permite a los adultos utilizar el monitor y reflexionar sobre las reglas y componentes lingüísticos; construir una 
gramática consciente y llevar a cabo el proceso de aprendizaje de una lengua. Esta ventaja de Gina sobre los niños también se puede explicar desde la teoría de Cummins que estudia el proceso 1lamado destreza lingüística cognoscitiva/académica, que consiste en recurrir a la experiencia de haber adquirido un idioma, su lengua materna, para aproximarse a la adquisición de una segunda lengua. Si no resultan suficientes las propuestas teóricas anteriores para explicar el aprendizaje de Gina de una segunda lengua, podemos recurrir a Scarcella e Higa quienes lo explican de la siguiente manera "para el desarrollo de una segunda lengua, el material lingüístico que procesan los adolescentes y los adultos es mejor que el que procesa el niño. Los mecanismos de conversación de los adolescente y los adultos, y el input generado gracias a éstos, pueden ser la causa de la ventaja que esos sujetos tienen en cuanto a la velocidad de adquisiciónaprendizaje durante las primeras etapas del proceso lingüístico". (p. 190)

Gina era una mujer dulce y atenta, siempre estuvo al tanto de sus compañeros y nunca pasó una clase en la que no se interesara por mis actividades personales, es decir contaba con lo que para Dulay son dos rasgos de personalidad que benefician el proceso de adquisición: la empatía y la confianza en sí mismo, recuerdo bien que como una niña terminaba sus ejercicios en clase y me los mostraba 1lena de orgullo, preguntando si estaban bien resueltos, convencida de que la respuesta generalmente sería "muy bien, Gina", con 1o cual una sonrisa iluminaba su cara y la compartía con los compañeros, quienes le correspondían con un gesto de aprobación y respeto, de esta manera, y de acuerdo con Krashen, sabemos que Gina encontró en ese grupo de nivel iniciación, las condiciones óptimas para satisfacer sus necesidades lingüísticas y afectivas.

Gardner y Lambert afirman que "para desarrollar una segunda lengua se necesita algo más que simplemente un buen oído, una buena experiencia, una inteligencia verbal y una aptitud favorable, se necesita tener además una variable socioafectiva positiva", (p. 204) algo que no poseía Iván, un alumno francés de aproximadamente 50 años de edad que había adquirido un buen grado de español, pero cuyo acento lo traicionaba pues, al parecer, su única motivación para tomar clases en el CEPE era obtener una visa que le permitiera permanecer en México cierto tiempo, lo que resultaba, cuando menos, muy curioso, porque vivía quejándose de México y los mexicanos, podría decirse entonces que consideraba el bilingüismo como un riesgo de pérdida de identidad, es decir como bilingüismo sustractivo. En el salón de clase escuchaba canciones como parte de los ejercicios y se negaba a contestarlos diciendo que "no era buena música" y que "no estaba acostumbrado a oír esas malas letras", 1o que reflejaba una ausencia total de motivación integrativa, la que Gliksman define como "el deseo de adquirir determinada lengua para volverse como los miembros prestigiados de la comunidad de esa segunda lengua" (p. 206) su motivación era instrumental, aquella que obedece a fines prácticos. Iván había fosilizado ya el nivel de español que había alcanzado, no tenía interés en corregir sus errores, no le gus- 
taba que yo monitoreara su desempeño en clase, evitaba la supervisión de su trabajo, le desesperaba la corrección de sus ejercicios y no atendía las observaciones y sugerencias que para mejorar su redacción le señalaba una y otra vez, todo lo cual me indicaba que se había quedado paralizado en una etapa pidginizada, ya que por pidginización se entiende la utilización de una segunda lengua con un propósito meramente comunicativo, separado de la funciones integrativa y expresiva propuestas por Shumann. El caso de Iván nos muestra cómo los rasgos psicológicos y la actitud de un estudiante afectan directamente la adquisición de una segunda lengua.

Sabemos que los alumnos utilizan una gran cantidad de estrategias de comunicación para llegar a la lengua meta, entre ellas están las que describiré con estos otros ejemplos: Kelen, estudiante checa de cuarto nivel, respondió de la siguiente manera a una pregunta sobre el papel social de la mujer de antes y de la actualidad en su país: "bueno, yo nunca me sentí oprimida, las mujeres en mi país siempre han tenido los mismos derechos y obligaciones que los hombres, aunque es más fácil que ellos se encarguen de algunas cosas como componer el coche, porque en mi país los hombres no han sido nunca machos, como he visto que a algunas de mis amigas mexicanas les prohíbe su esposo fumar. Yo no fumo ahora porque estoy embarazada pero mi esposo no hay cosas que no me permita..." y la respuesta se convirtió en una charla sobre lo dañino que es el cigarro durante el embarazo. La estrategia que Kelen utilizó fue la omisión de tópico, quizá no tenía nada que aportar sobre el cambio del papel de la mujer porque para ella no ha sido un problema que refleje la realidad de su país, así que orientó la conversación hacia un tema de su interés, determinado tal vez en buena medida por su condición actual. Otra comportamiento interesante era el de Keiko, alumna japonesa, que generalmente respondía con una pregunta a preguntas cuya respuesta no podía dar o que temía contestar incorrectamente, de modo que en lugar de responder, preguntaba el significado de tal o cual palabra, y desviaba con habilidad mi atención hacia darle alguna explicación, recurría a la estrategia de ceder la tarea de hablar.

En lo que toca a estrategias de aprendizaje, es muy común observar la cantidad de muletillas que algunos de los alumnos extranjeros adquieren, como es el caso del estorboso "este", pero hay una que ha llamado mi atención desde hace tiempo, la empleada por Harald, brillante alumno alemán, que pronunciaba de manera muy peculiar la expresión "como digo, digamos" porque seguramente la escuchó frecuentemente durante el proceso de adquisición de boca de una persona a cuya influencia era sensible y la integró a su acervo lingüístico por medio de la estrategia de memorización de modelos prefabricados.

Guilford nos dice que hay aproximadamente ciento veinte capacidades mentales que conforman la estructura del intelecto, de las cuales los profesores conocemos solamente algunas; estos textos 1laman nuestra atención para atender la responsabilidad que como tales tenemos, para reflexionar sobre la 
importancia que tiene la actualización de nuestros conocimientos teóricos y prácticos, para poder facilitar el aprendizaje del alumno, ya que como subraya Corder: "La enseñanza eficiente de un idioma debería trabajar con, y no contra, de los procesos naturales, facilitando y estimulando el aprendizaje en vez de obstaculizarlo. Los maestros y los materiales de enseñanza se deberían adaptar al alumno en vez de que sea a la inversa". (p. 247) Y añade que aunque se admita que no podemos enseñar realmente un idioma, sí podemos facilitar las condiciones para que éste se desarrolle en la mente de nuestros alumnos de manera espontánea y natural. Para facilitar esas condiciones debemos hacer materiales de interés para los alumnos, materiales auténticos que los guíen a través de la cultura y de la lengua meta de manera amena y atractiva, no para que la vean como un conjunto de reglas a seguir sino como algo de lo que desean formar parte.

Las reflexiones anteriores proceden de mi experiencia como profesora en el Centro de Enseñanza para Extranjeros y de la lectura de los tres capítulos mencionados al inicio de este resumen, $\mathrm{y}$ que, como señalé anteriormente, se trata de tres recorridos puntuales y sugerentes sobre diversos factores que afectan o propician la adquisición de una segunda lengua y contribuyen a resolver un buen número de preguntas sobre la adquisición de lenguas que uno nunca se atrevió a imaginar.

Sandra L. Cruz Iturribarri CEPE-UNAM 